\title{
Clinical and scintigraphic assessment of the role of endoscopic sphincterotomy in the treatment of sphincter of Oddi dysfunction
}

University Department of Surgery, Western Infirmary, Glasgow G M Fullarton

A Campbell

W R Murray

West of Scotland Health Boards Department of

Clinical Physics and Bioengineering, Glasgow T Hilditch

Correspondence to: $\mathrm{Mr} \mathrm{G}$ Fullarton, University Fullarton, University Wepartment of Surgery, Western Intrin

Accepted for publication 17 April 1989

\begin{abstract}
Postcholecystectomy pain caused by sphincter of Oddi dysfunction remains a difficult condition to treat. Endoscopic sphincterotomy has been recommended for those patients with confirmed sphincter of Oddi motor abnormalities. We have studied sphincter of Oddi dysfunction patients to evaluate the effects of endoscopic sphincterotomy on both clinical symptoms and previously reported scintigraphic parameters to determine the efficacy of this method of treatment. Nine postcholecystectomy patients (seven women: two men, median age 59 years) with clinical and manometric evidence of sphincter of Oddi dysfunction underwent endoscopic sphincterotomy for persisting biliary type pain. Each patient had scintigraphy before and eight weeks after endoscopic sphincterotomy. The patients symptomatic response was assessed independently at three monthly intervals after endoscopic sphincterotomy. Scintigraphic analysis showed that the $\mathbf{T}_{\text {max }}$ (time in minutes to maximum counts) was significantly reduced from 25.0 (20-36) (median [range]) before endoscopic sphincterotomy to $15.0(13-25)$ after endoscopic sphincterotomy $(p<0.01)$. Seven of nine $(\mathbf{7 8 \%})$ sphincter of Oddi dysfunction patients had significant improvement in their symptoms after a mean follow up period of 12 months (range 6-19) although only six of nine were totally pain free. These results suggest that endoscopic sphincterotomy in manometrically confirmed sphincter of Oddi dysfunction improves bile drainage as measured by quantitative cholescintigraphy and is associated with at least short term symptom relief in the majority of patients.
\end{abstract}

Sphincter of Oddi dysfunction is a recognised cause of postcholecystectomy pain in $9-14 \%$ of cases, ${ }^{12}$ although its true prevalence remains unclear. It is, however, a difficult condition to diagnose requiring endoscopic biliary manometry to confirm sphincter pressure abnormalities. ${ }^{3-5}$ We have recently reported that quantitative cholescintigraphy using ${ }^{99 \mathrm{~m}} \mathrm{Tc}$ DISIDA can detect alterations in labelled bile flow in postcholecystectomy patients with manometric evidence of sphincter of Oddi dysfunction. ${ }^{6}$ In these patients endoscopic sphincterotomy has been recommended as the treatment of choice ${ }^{278}$ although few clear therapeutic guidelines exist at present. ${ }^{9}$ In addition cholescintigraphy may provide a simple non-invasive method to quantify the effects of endoscopic sphincterotomy on biliary dynamics. ${ }^{10}$

The aim of this study was therefore to examine the effects of endoscopic sphincterotomy on symptoms and scintigraphic parameters in postcholecystectomy patients with manometric evidence of sphincter of Oddi dysfunction to determine the efficacy of this method of treatment.

\section{Methods}

\section{PATIENTS}

Nine postcholecystectomy patients (seven women, two men) with a median age of 59 years (range 35-74) presented with clinically suspected sphincter of Oddi dysfunction (recurrent biliary type pain \pm transient liver function test changes \pm dilated common bile duct at ERCP) and all underwent endoscopic biliary manometry to confirm sphincter motor abnormalities. ${ }^{6}$ Eight patients had transient abnormalities in either transaminases and/or alkaline phosphatase associated with attacks of pain (Table I) although these subsequently all returned to normal. All nine study patients had a dilated common bile duct ( $\geqslant 12 \mathrm{~mm}$ ) at time of ERCP (Table I). Patients presented at a median time interval of five years (range eight months26 years) after cholecystectomy with a median symptom free interval after surgery of two years (range three months-22 years).

\section{ENDOSCOPIC BILIARY MANOMETRY}

TECHNIQUE

Endoscopic biliary manometry was performed using an Arndorfer based capillary perfusion system with a reservoir pressure of $400 \mathrm{mmHg}$ producing a catheter flow rate of $0.25 \mathrm{ml} / \mathrm{min}$ of distilled water. Under study conditions this

TABLE I Clinical, biochemical, and radiological features of sphincter of Oddi dysfunction group

\begin{tabular}{|c|c|c|c|c|c|c|}
\hline \multirow[b]{2}{*}{ Subject } & \multirow{2}{*}{$\begin{array}{l}\text { Age } \\
\text { (years) }\end{array}$} & \multirow[b]{2}{*}{ Sex } & \multicolumn{3}{|c|}{ Transient $L F T$ changes } & \multirow{2}{*}{$\begin{array}{l}C B D \\
\text { diameter } \\
(\mathrm{mm})\end{array}$} \\
\hline & & & $A S T(U / l)$ & $A L T(U / l)$ & $A L P(U / l)$ & \\
\hline MN & 56 & $\mathbf{F}$ & 54 & 35 & 200 & 15 \\
\hline IS & 74 & $\mathrm{~F}$ & 32 & 40 & 158 & 15 \\
\hline EB & 59 & $\mathrm{~F}$ & 200 & 200 & 250 & 13 \\
\hline $\mathrm{AB}$ & 53 & $\mathrm{~F}$ & $\mathbf{N}$ & $\mathrm{N}$ & $\mathbf{N}$ & 12 \\
\hline $\mathrm{AM}$ & 73 & M & 17 & 29 & 196 & 16 \\
\hline $\mathrm{JM}$ & 71 & M & 145 & 152 & 154 & 12 \\
\hline MF & 35 & $\mathrm{~F}$ & 58 & 61 & 67 & 13 \\
\hline $\mathrm{EM}$ & 60 & $\mathrm{~F}$ & 52 & 197 & 312 & 15 \\
\hline $\mathrm{RM}$ & 59 & $\mathrm{~F}$ & 86 & 170 & 228 & 16 \\
\hline
\end{tabular}

Normal range AST (10-35), ALT (10-50), ALP (35-130). AST = aspartate aminotransferase; $\mathrm{ALT}=$ alanine aminotransferase, $\mathrm{ALP}=$ alkaline phosphatase $\mathrm{CBD}=$ common bile duct; $\mathrm{LFT}$ liver function tests; $\mathrm{N}=$ normal value. 
equipment gave a postocclusion pressure rise rate of $450 \mathrm{mmHg} / \mathrm{s}$. Polyethylene triple lumen catheters were used (Arndorfer Medical Specialties Inc, Greendale, Wisconsin, USA) with an outer diameter of $1.7 \mathrm{~mm}$ and inner luminal diameter of $0.5 \mathrm{~mm}$. Each catheter had three side holes $2 \mathrm{~mm}$ apart, the most distal hole being $5 \mathrm{~mm}$ from the catheter tip. Catheters had eight black rings $1 \mathrm{~mm}$ wide at $2 \mathrm{~mm}$ intervals to determine the depth of insertion of the catheter into the sphincter of Oddi.

Biliary manometry was performed in the fasting state at time of ERCP under diazepam sedation only (5-10 mg iv). No analgesia or smooth muscle relaxants were used. With the patient prone a station pull through technique was used to measure active sphincter segment pressures simultaneously for at least two minutes with duodenal pressure referenced as zero. The catheters position in the bile duct was confirmed by contrast injection after manometry. Sphincter basal pressure was calculated as the mean pressure at base of phasic contractions over a two minute recording period. Phasic wave amplitude was calculated as the mean pressure rise above basal pressure over the two minute recording period.

\section{MANOMETRY CONTROL GROUP}

Our manometric control group consisted of 18 patients (16 women, two men, median age 49 years, range 27-92). In this group of patients 12 had common bile duct stones (all postcholecystectomy and six had no evidence of pancreaticobiliary disease. These six patients had all been extensively investigated for relatively minor upper gastrointestinal complaints with no abnormality being detected in the gastrointestinal tract. Their symptoms were attributed to irritable bowel syndrome in five, one patient was subsequently found to have porphyria. Previous manometric studies have validated the use of patients with common bile duct stones as control subjects."12 Using our manometry control data we considered sphincter of Oddi dysfunction to be present if sphincter of Oddi mean basal pressure and/or phasic pressure exceeded the mean control values by $>2$ SD (Table II). All nine study patients had manometric evidence of sphincter of Oddi dysfunction based on this criteria.

\section{STUDY PROTOCOL}

These nine patients with clinical and manometric evidence of sphincter of Oddi dysfunction were then entered into the study. All were clinically well at time of study and routine liver function tests (serum bilirubin, alkaline phosphatase, and transaminases) were normal in all subjects before cholescintigraphy.

TABLE II Sphincter of Oddi pressures in dysfunction group

\begin{tabular}{lll}
\hline & Basal $(\mathrm{mmHg})$ & Phasic $(\mathrm{mmHg})$ \\
\hline SO dysfunction $(\mathrm{n}=9)$ & $26 \cdot 0(20-42)$ & $141 \cdot 0(112-224)$ \\
Controls $(\mathrm{n}=18)$ & $14 \cdot 0(8-20)(22 \cdot 3)$ & $82 \cdot 5(54-102)(110)$
\end{tabular}

Median (ranges). Figures in parentheses indicate our upper limit of normal based on control means +2 SD.
Each patient underwent cholescintigraphy with ${ }^{{ }^{9 m} \mathrm{~T}} \mathrm{~T}$-DISIDA before and eight weeks after endoscopic sphincterotomy. Endoscopic sphincterotomy was performed in all patients by a single operator (WRM) using a traction type papillotomy knife (Olympus Corp, Tokyo, Japan) dividing the sphincter from the ampullary orifice to the transverse duodenal mucosal fold. ${ }^{13}$ Using this technique we demonstrated ablation of sphincter of Oddi basal pressure with zero pressure gradient between the duodenum and common bile duct in the first four patients treated (MN, EM, IS, AM). Each patients symptom status was assessed by an independent observer at three monthly intervals after endoscopic sphincterotomy.

\section{SCINTIGRAPHIC TECHNIQUE}

After an overnight fast $150-\mathrm{MBq}$ of ${ }^{99 \mathrm{~m}} \mathrm{Tc}$ DISIDA (Hepatolite, Dupont UK, Ltd) were given at time zero. Imaging was carried out using a large field gamma camera (Siemens ZLC 750) interfaced to a computer (Nodecrest Limited). Data were recorded with the subject supine under the gamma camera as a continuous series of 60 frames each of one minute duration and stored on computer disk for later analysis.

Regions of interest were drawn around the entire hepatobiliary system (liver and extrahepatic bile ducts) and activity/time curves created by computer analysis for this region of interest after correction for radioactive decay. The common bile duct was also outlined as a separate region of interest, however, this was often technically difficult because of duodenal overlap. In addition preliminary analysis of this region of interest produced similar results to those of the entire hepatobiliary system. The simpler hepatobiliary region of interest was therefore used through the study. Results for this hepatobiliary region of interest were expressed as (Fig 1): (1) $\mathrm{T}_{\text {MAX }}$ (Time in minutes from zero to maximum counts) reflecting hepatic uptake and early biliary clearance. (2) E45 (\% biliary emptying at 45 minutes) - that is, activity cleared at 45 minutes as a percentage of the maximum counts in the region of interest. (3) E60 (\% biliary emptying at 60 minutes) - that is, activity cleared at 60 minutes as a percentage of the maximum counts in the region of interest.

Analysis was performed by staff unaware of the patients clinical condition.

Statistical analysis was performed using paired Wilcoxon's rank-sum test ( 2 sided) and significance was taken at the $5 \%$ level $(\mathrm{p}<0.05)$.

\section{Results}

SCIN T I G RAPHY

Results for $\mathrm{T}_{\text {MAX }}, \mathrm{E} 45$ and E60 before and after endoscopic sphincterotomy are shown in Table III.

$\mathrm{T}_{\text {MAX }}$ values decreased in eight of nine patients after endoscopic sphincterotomy $(\mathrm{p}<0.01)$ and remained unchanged in one patient (Fig 2). E45 was also significantly increased after sphincterotomy in seven of nine patients $(p<0.05)$. 
Figure 1: Representative activity/time curve demonstrating parameters measured. $T_{\mathrm{MAX}}=$ time in minutes from zero to maximum counts. $E 45=\%$ biliary emptying from maximum at 45 minutes. $E 60=\%$ biliary emptying from maximum at 60 minutes.

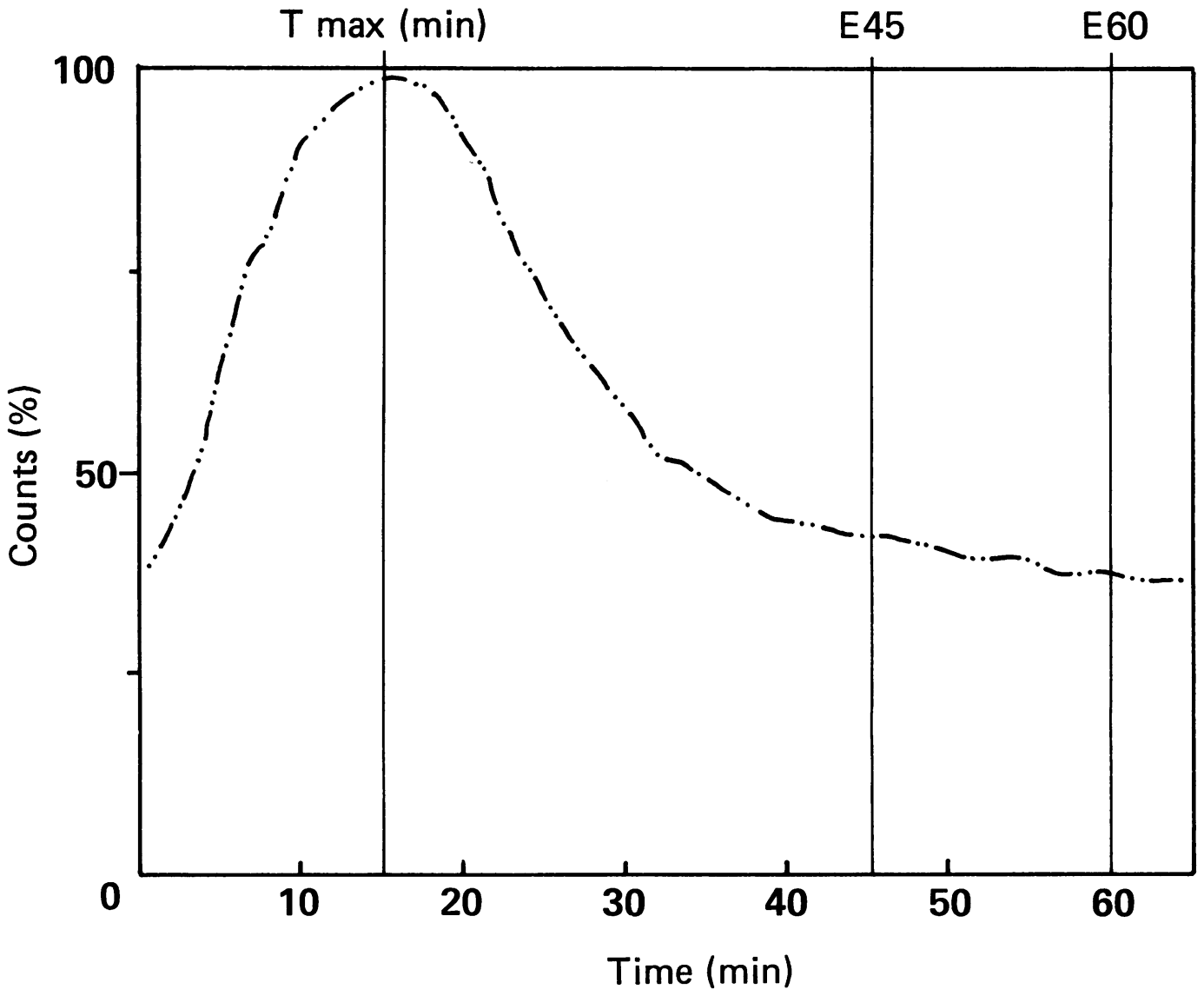

The effect of endoscopic sphincterotomy on quantitative biliary dynamics is best seen in the activity/time curves from a representative sphincter of Oddi dysfunction patient (Fig 3).

\section{CLINICAL RESPONSE}

Patients have been assessed at a median time period of 12 months (range 6-19) after endoscopic sphincterotomy. Seven of nine (78\%) patients were symptomatically improved after endoscopic sphincterotomy although only six were totally asymptomatic at time of review (Table IV). Two patients (EM, RM) had unchanged symptoms after sphincterotomy despite improvement in their scintigraphic parameters (Fig 2) and confirmation of sphincter of Oddi ablation by repeat endoscopic biliary manometry. The two patients (EM, RM) who failed to respond to endoscopic sphincterotomy have both since been extensively investigated by barium series, upper and lower gastrointestinal endoscopy, abdominal ultrasound and 24 hour oesophageal $\mathrm{pH}$ monitoring. This has resulted in possible alternative diagnoses in both patients (EM - diverticular disease, RM - gastrooesophageal reflux). Overall therefore endoscopic sphincterotomy was beneficial in seven of nine $(78 \%)$ patients with only two of nine (22\%) patients demonstrating no symptom

TABLE III Scintigraphic results $(n=9)$

\begin{tabular}{llll}
\hline & $T_{\text {MAX }}(\min )$ & $E 45(\%)$ & $E 60(\%)$ \\
\hline Pre endoscopic sphincterotomy & $25 \cdot 0(20-36)$ & $24 \cdot 8(10-52)$ & $37 \cdot 3(16-69)$ \\
Post endoscopic sphincterotomy & $15 \cdot 0(13-25) \dagger(20)$ & $36 \cdot 7(19-45)^{\star}(26 \cdot 1)$ & $48 \cdot 9(32-66)$
\end{tabular}

${ }^{\star} p<0.05 ; \mathrm{tp}<0.01$. Medians (ranges). Figures in parentheses indicate our upper and lower limits of normal based on control means $\pm 2 \mathrm{SD}^{\circ}$.
not improvement. Patient 3 (EB) developed recurrent symptoms 12 months after endoscopic sphincterotomy and had manometrically confirmed sphincter restenosis (basal pressure 58 $\mathrm{mmHg}$, phasic pressure $116 \mathrm{mmHg}$ ). Repeat ${ }^{99 m} \mathrm{Tc}$-DISIDA scan at this time revealed a $\mathrm{T}_{\text {MAX }}$ of 31 minutes compared with 20 minutes after sphincterotomy. A further endoscopic sphincterotomy was performed and repeat scintigraphy eight weeks later showed a reduction in $\mathrm{T}_{\text {MAX }}$ to 15 minutes (within our normal range). The patient remains significantly improved up to three months following this second sphincterotomy.

\section{Discussion}

This study has shown that in postcholecystectomy patients with manometric evidence of sphincter of Oddi dysfunction, endoscopic sphincterotomy improves bile drainage as measured indirectly by quantitative cholescintigraphy and is associated with at least short term symptom relief in the majority of patients.

The introduction of endoscopic biliary manometry has been associated with increased recognition of sphincter of Oddi dysfunction as a cause of postcholecystectomy pain in patients with no demonstrable pancreaticobiliary abnormalities using conventional imaging techniques. ${ }^{3-5} 1+15$ The term sphincter of Oddi dysfunction has been used to encompass all identifiable manometric disorders including both fixed fibrotic sphincter of Oddi stenosis and true motor dysfunction. Although the pathogenesis of this condition is unclear cholecystectomy may predispose to sphincter of Oddi dysfunction either through direct sphincter trauma $^{16}$ (leading to 


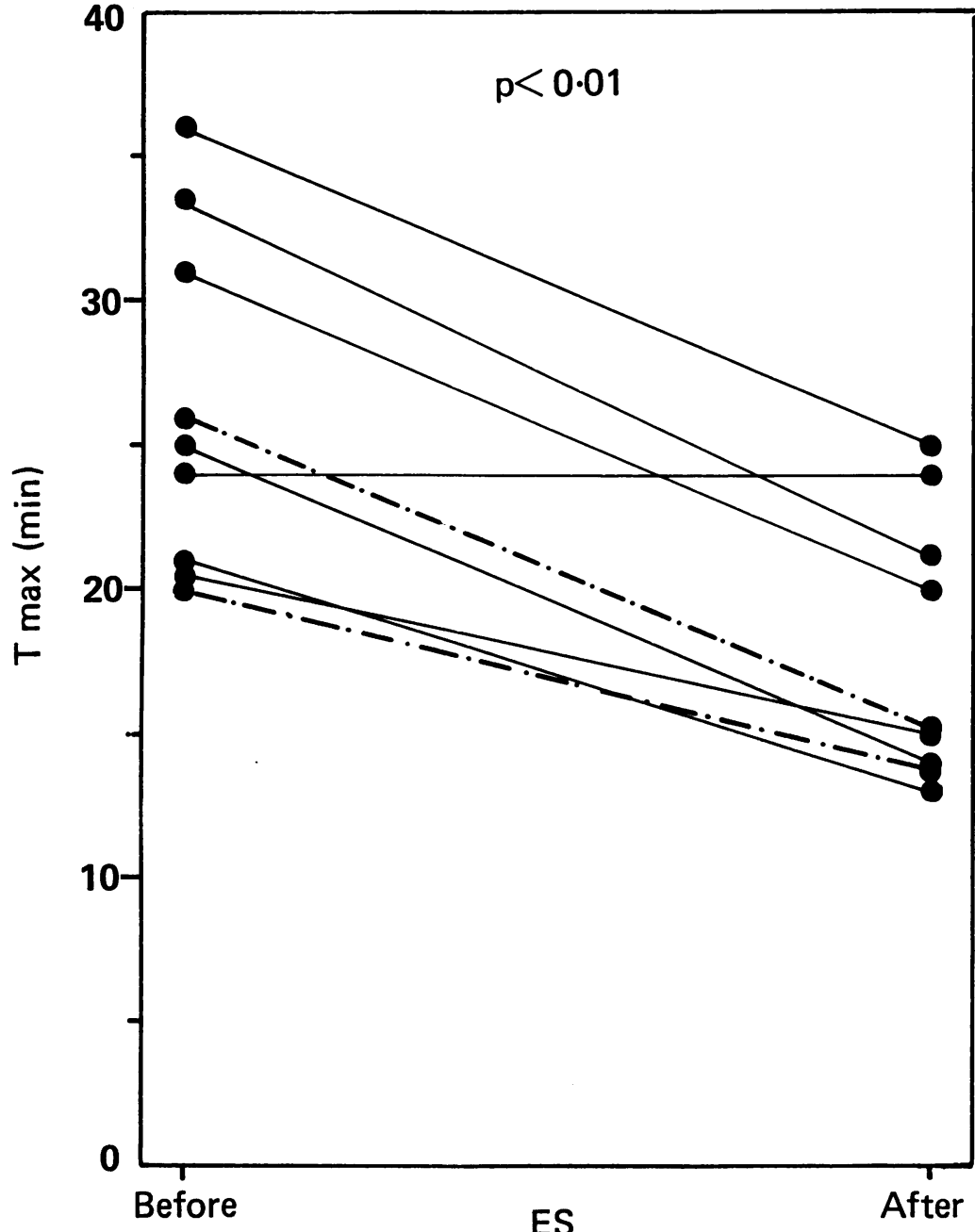

fibrotic stenosis) or possibly through interference with sphincter of Oddi control mechanisms. Sphincter of Oddi function appears to be closely regulated by both neural ${ }^{17}$ and hormonal ${ }^{18}$ pathways. Interference with inhibitory neural networks around the cystic duct/choledochal iunction has been shown to increase resting sphincter of Oddi pressure in cats. ${ }^{19}$ In addition a paradoxical hormonal response to cholecystokinin has also been suggested as a possible factor in the pathogenesis of sphincter of Oddi dysfunction. ${ }^{20}$ The increase in common bile duct pressures demonstrated after cholecystectomy may therefore reflect such alterations in sphincter of Oddi function. ${ }^{21}$ It remains unclear as to whether sphincter of Oddi abnormalities may occur before cholecystectomy although limited evidence exists. ${ }^{22}$

The mechanism by which sphincter of Oddi dysfunction produces biliary type pain is unclear but may result directly from high pressure sphincter phasic contractions (sphincter spasm) akin to oesophageal spasm or indirectly by producing transient bile duct obstruction and subsequent dilatation. ${ }^{23}$

In postcholecystectomy patients with manometric evidence of sphincter of Oddi dysfunction sphincter division by either surgical ${ }^{24}$ or endoscopic $^{278}$ means has been recommended as treatment although clear guidelines are limited. Endoscopic sphincterotomy as been shown to virtually abolish sphincter of Oddi pressures for at least two years ${ }^{25}$ and may therefore be expected to improve sphincter of Oddi dysfunction pain if increased basal pressure is the primary pathogenic feature. Geenen et al in the only random-
Figure 2: $T_{\mathrm{MAX}}$ values before and eight weeks after endoscopic sphincterotomy $(E S)$ in nine patients with manometrically confirmed sphincter of Oddi dysfunction. The two patients (EM and $R M)$ who had continuing symptoms post-ES are indicated by hatched lines.

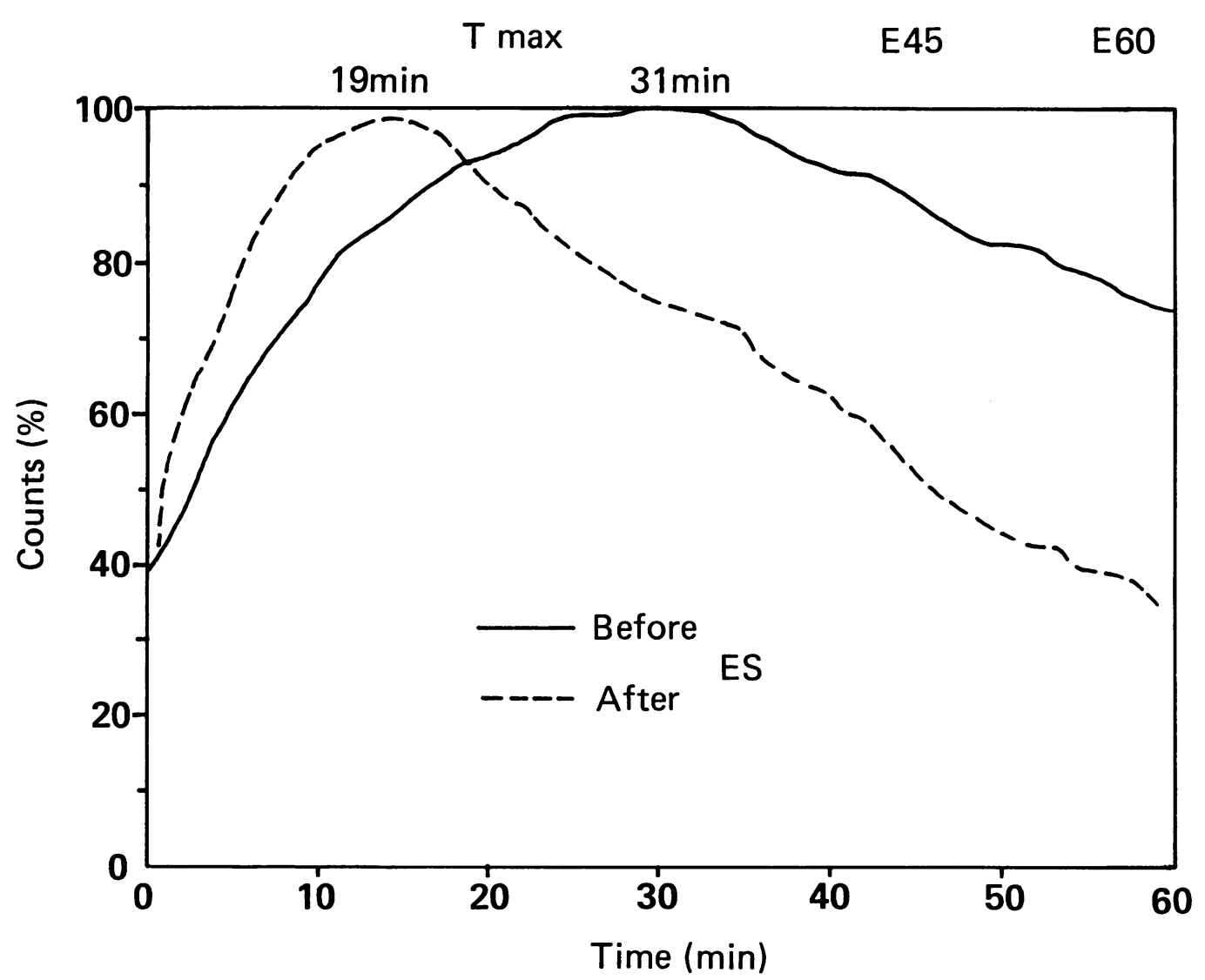

Figure 3: Representative activity/time curves in a sphincter of Oddi dysfunction patient before and 8 weeks after endoscopic sphincterotomy $(E S)$ showing changes in quantitative biliary dynamics. 
TABLE IV Clinical response after endoscopic sphincterotomy

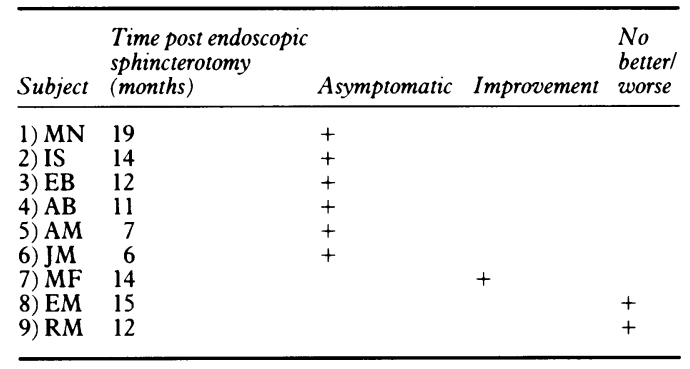

ised controlled clinical trial to date, have shown that $91 \%$ of postcholecystectomy patients with manometrically confirmed sphincter of Oddi dysfunction were improved by endoscopic sphincterotomy up to four years later. ${ }^{9}$ Our study adds further evidence to support a beneficial role for endoscopic sphincterotomy in producing at least short term symptom relief in patients with sphincter of Oddi dysfunction.

Quantitative cholescintigraphy can detect alterations in labelled bile flow in postcholecystectomy patients with sphincter of Oddi dysfunction. ${ }^{6102627}$ This study confirms that endoscopic sphincterotomy can improve bile flow as measured indirectly by scintigraphy in such patients. $T_{\text {MAX }}$, which we consider the most sensitive indicator of delayed bile flow, returned to within our normal control range in seven out of nine patients eight weeks after endoscopic sphincterotomy. Although endoscopic biliary manometry remains the gold standard for confirmation of sphincter of Oddi pressure ablation by endoscopic sphincterotomy this remains a specialised technique which is limited to a few centres only. Quantitative cholescintigraphy may therefore offer a simple, non-invasive technique for assessing improvements in bile flow after endoscopic sphincterotomy in sphincter of Oddi dysfunction patients. It may also be of value in screening such patients if symptoms recur for evidence of sphincter restenosis as illustrated by patient 3 . The effect of increasing age on both sphincter of Oddi function and scintigraphic parameters is, however, unknown and requires further investigation particularly as patients presenting with sphincter of Oddi dysfunction may be elderly.

In conclusion endoscopic sphincterotomy in manometrically confirmed sphincter of Oddi dysfunction improves bile flow as measured indirectly by quantitative cholescintigraphy and is associated at least short term symptom relief in the majority of patients. We therefore consider that endoscopic sphincterotomy should be regarded as the current treatment of choice in postcholecystectomy patients with manometric evidence of sphincter of Oddi dysfunction.

Our thanks to Miss Yvonne Galbraith for typing the manuscript.
1 Bar-Meir S, Halpern Z, Bardan E, Gilat T. Frequency of papillary dysfunction among cholecystectomized patients. Hepatology 1984; 4: 328-30.

2 Neoptolemos JP, Bailey IS, Carr-Locke DL. Sphincter of Oddi dysfunction: results of treatment by endoscopic sphincterotomy. BrF Surg 1988; 75: 454-9.

3 Bortolotti M, Caletti GC, Brocchi E, et al. Endoscopic manometry in the diagnosis of the post-cholecystectomy pain syndrome. Digestion 1983; 28: 153-7.

4 Toouli J, Roberts-Thomson IC, Dent J, Lee J. Manometric disorders in patients with suspected sphincter of Oddi dysfunction. Gastroenterology 1985; 88: 1243-50.

5 Bar-Meir S, Geenen JE, Hogan WJ, Dodds WJ, Stewart ET, Arndorfer RC. Biliary and pancreatic duct pressures measured by ERCP manometry in patients with suspected papillary stenosis. Dig Dis Sci 1979; 24: 209-13.

6 Fullarton GM, Allan A, Hilditch T, Murray WR. Quantitative usm Tc-DISIDA scanning and endoscopic biliary manometry in sphincter of Oddi dysfunction. Gut 1988; 29: 1397-401.

7 in sphincter of Oddi dysfunction. Gut 1988; 29: 1397-401. for disabling biliary-type pain after cholecystectomy effective? Gastrointest Endosc 1985; 31: 370-3.

8 Aronchick CA, Long WB, Soloway RD. Endoscopic biliary manometry and a modified morphine prostigmine test as predictors of clinical response to sphincterotomy in biliary dyskinesia. Gastrointest Endosc 1984; 30: 140.

9 Geenen JE, Hogan WJ, Dodds WJ, Toouli J, Venu RP. The efficacy of endoscopic sphincterotomy after cholecystectomy in patients with sphincter of Oddi dysfunction. $N E n g l$ f Med 1989; 30: 82-7.

10 Shaffer EA, Hershfield NB, Logan K, Kloiber R. Cholescintigraphic detection of functional obstruction of the sphincter of Oddi. Gastroenterology 1986; 90: 728-33.

11 Toouli J, Geenen JE, Hogan WJ, Dodds WJ, Arndorfer RC. Sphincter of Oddi motor activity: a comparison between patients with common bile duct stones and controls. Gastropatients with common bile
enterology 1982; 82: 111-7.

12 De Masi E, Corazziari E, Habib FI, et al. Manometric study of the sphincter of Oddi in patients with and without common bile duct stones. Gut 1984; 25: 275-8.

13 Carr-Locke DL, Cotton PB. Biliary tract and pancreas. BrMed Bull 1986; 42: 257-64.

14 Funch-Jensen P, Kruse A, Csendes A, Oster MJ, Andrup E. Biliary manometry in patients with post-cholecystectomy syndrome. Acta Chir Scand 1982; 148: 267-8.

15 Tanaka M, Ikeda S, Matsumoto S, Yoshimoto H, Nakayama F. Manometric diagnosis of sphincter of Oddi spasm as a cause of post-cholecystectomy pain and the treatment by cause of post-cholecystectomy pain and the treatment
endoscopic sphincterotomy. Ann Surg 1985; 202: 712-9.

16 Schuppisser JP, Tondelli P. Papillary stenosis. In: Salmon PR, ed. Gastrointestinal endoscopy. Advances in diagnosis and therapy. Volume One. London: Chapman and Hall, 1984: 181-92.

17 Behar J, Biancani P. Neural control of the sphincter of Oddi: a physiological role of 5-hydroxytryptamine on the regulation of basal sphincter of Oddi motor activity in the cat. $\mathcal{F}$ Clin Invest 1983; 72: 551-9.

18 Sarles JC. Hormonal control of sphincter of Oddi. Dig Dis $S c i$ 1986; 31: 208-12.

19 Thune A, Thornell E, Svanvik J. Reflex regulation of flow resistance in the feline sphincter of Oddi by hydrostatic pressure in the biliary tract. Gastroenterology 1986; 91: 1364-9.

20 Rolny P, Arleback A, Funch-Jensen P, Kruse A, Ravnsbaeck J, Jarnerot G. Paradoxical response of sphincter of Oddi to intravenous injection of cholecystokinin or ceruletide. intravenous injection of cholecystokinin or ceruletide.
Manometric findings and results of treatment in biliary Manometric findings and results
dyskinesia. Gut 1986; 27: 1507-11.

21 Tanaka M, Ikeda S, Nakayama F. Change in bile duct pressure responses after cholecystectomy: loss of gallbladder as a pressure reservoir. Gastroenterology 1984; 87: 1154-9.

22 Sunderland GT, Morran CG, Carter DC. Sphincter of Oddi motility in acalculous biliary pain [Abstract]. Gut 1987; 28: A1384

23 Lasson A, Fork FT, Tragardh B, Zederfeldt B. The postcholecystectomy syndrome: bile ducts as pain trigger zone. Scand $\mathcal{F}$ Gastroenterol 1988; 23: 265-71.

24 Moody FG, Becker JM, Potts JR. Transduodenal sphincteroplasty and transampullary septectomy for postcholecystectomy pain. Ann Surg 1983; 197: 627-36.

25 Geenen JE, Toouli J, Hogan WJ, et al. Endoscopic sphincterotomy: follow-up evaluation of effects on the sphincterotomy: follow-up evaluation of effects
sphincter of Oddi. Gastroenterology 1984; 87: 754-8.

26 Roberts-Thomson IC, Toouli J, Blanchett W, Lichtenstein M, Andrews JT. Assessment of bile flow by radioscintigraphy in patients with biliary-type pain after cholecystectomy. Aust patients with biliary-type pain
$N Z \mathcal{Y}$ Med 1986 16: 788-93.

27 Darweesh RMA, Dodds WJ, Hogan WJ, et al. Efficacy of quantitative hepatobiliary scintigraphy and fatty-meal sonography for evaluating patients with suspected partial common duct obstruction. Gastroenterology 1988; 94: 77986. 